\title{
Summary of Results from Space Shuttle Main Engine Off-Nominal Testing
}

\author{
James F. Horton ${ }^{\dagger}$ Jeffrey M. Megivern ${ }^{\dagger}$, Leslie M. McNutt ${ }^{*}$ \\ ${ }^{\dagger}$ Pratt \& Whitney Rocketdyne, Canoga Park, California, USA \\ *NASA Marshall Space Flight Center, Huntsville, Alabama, USA
}

\begin{abstract}
This paper is a summary of Space Shuttle Main Engine (SSME) offnominal testing that occurred during 2008 and 2009. During the last two years of planned SSME testing at Stennis Space Center, Pratt \& Whitney Rocketdyne worked with their NASA MSFC customer to systematically identify, develop, assess, and implement challenging test objectives in order to expand the knowledge of one of the world's most reliable and highly tested large rocket engine. The objectives successfully investigated three main areas of interest - expanding engine performance margins, demonstrating system operational capabilities, and establishing ground work for new rocket engine technology. The testing gave the Space Shuttle Program new options to safely fly out the flight manifest and provided Pratt \& Whitney Rocketdyne and NASA new insight into the operational capabilities of the SSME, capabilities which can be used in assessing potential future applications of the RS-25 engine.
\end{abstract}

\section{INTRODUCTION}

The Space Shuttle Main Engine (also known as the RS-25) is one of the world's most reliable and highly tested large rocket engine ever built. The SSME has achieved 100 percent flight success with a demonstrated reliability exceeding 0.9996 in over 1,000,000 seconds of hot-fire experience [4]. However, even after an extensive forty year test program, many aspects and questions remained about the engine's versatility beyond the original scope of design. As a result, in 2006, Pratt \& Whitney Rocketdyne (PWR) management requested the engineering staff demonstrate the following:

- Safety of existing flight rules and potential off-nominal operation

- SSME capabilities to expanding the potential envelope of operation

- Exercise the critical skills of current engineers and provide valuable training for new engineers through planning and implementing of challenging objectives safely

Shortly thereafter, in March 2007, the SSME Project was requested to "piggy-back" objectives that could expand the understanding of the SSME for potential usage in future exploration problems. Analysis was performed during a 5-week SSME Upper-Stage Gap Filler study and illustrated that the SSME could be used as a back-up for the J-2X (as an ARES 1 upper-stage engine) until that engine was ready for production. The review identified potential areas of testing to be performed to support the analysis and lower the risk of implementation. In September 2007, the MSFC SSME Project team suggested that test objectives should also be evaluated for their contributions that improve the general understanding of rocket engine physics as well as objectives that might potentially glean useful information for J-2X development. Thus the scope and direction of the testing was broadened in 2008 \& 2009 to: 
- Expand the operational limits of the SSME for space shuttle flights

- Demonstrate the technical feasibility of using an SSME for an alternate rocket propulsion application

- Provide general large rocket engine performance characteristics.

Twenty two of the last twenty four planned SSME tests at SSC hotfired with off-nominal objectives; items which successfully investigated three general main areas of interest: expanding the performance margins of the engine, demonstrating the operational capabilities of the system, and establishing the ground work for new technology. For most tests, these objectives were also demonstrated in parallel with flight program objectives, such as critical component acceptance testing, i.e. green run, making the implementation even more difficult. The test series utilized two development Block II SSMEs (engines 0525 and 0528) as well as one flight Block II SSME (engine 2061). All objectives were performed at Stennis Space Center's A-2 test stand.

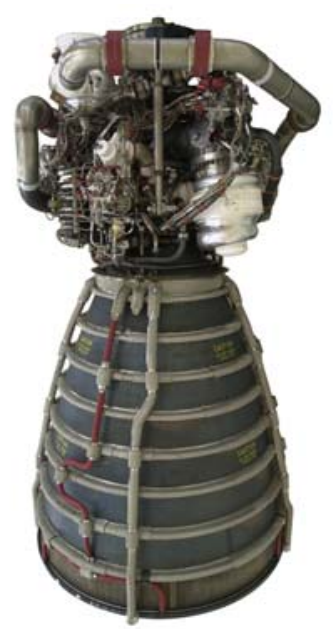

Figure 1. Block II SSME (RS-25D)

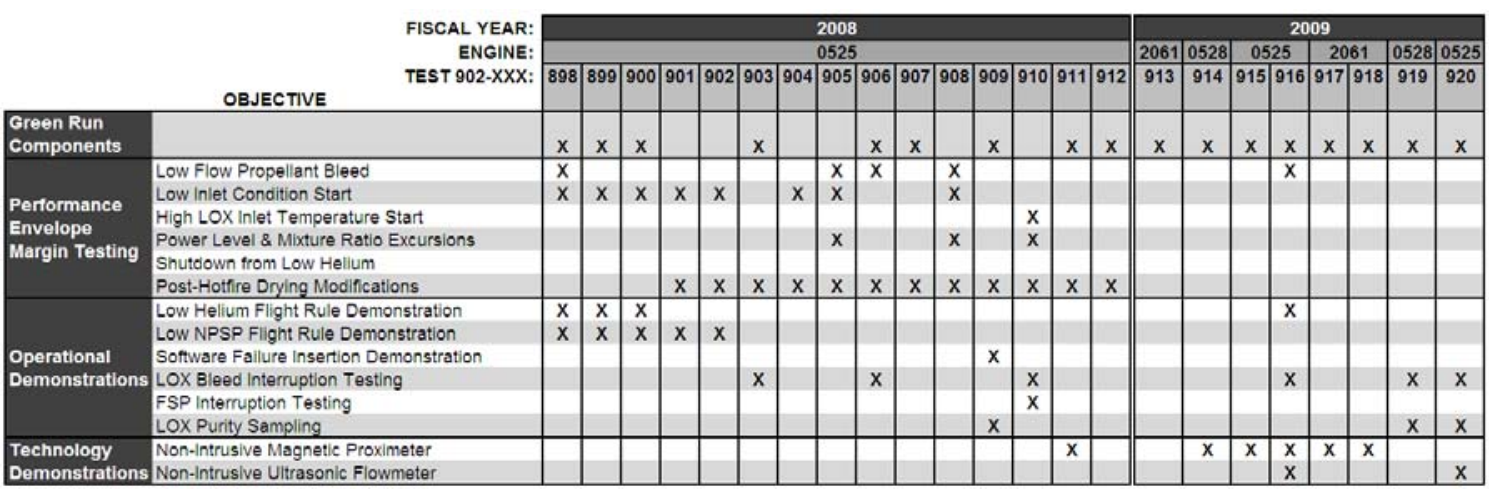

Figure 2. Fiscal Year 2008 \& 2009 Off-Nominal Test Matrix

\section{PERFORMANCE ENVELOPE TESTING}

\section{Low Flow Propellant Bleed}

Achieving proper thermal conditioning of the engine by utilizing a lower propellant bleed flowrate was identified as a beneficial objective to demonstrate SSME capabilities beyond nominal operation. Propellant tank orientations vary between launch vehicles and an altered configuration would require different chill conditions than those used on the Space Shuttle Program.

Given that the engine was acknowledged to be a possible upper stage engine replacement until the $\mathrm{J}-2 \mathrm{X}$ rocket engine was ready for production in 2007, testing was baselined with meeting the Ares I Interface Control Document (ICD) vehicle requirements. The cryogenic bleed mass flowrate is proportional to the calculated differential pressure drop across the engine propellant system with respect to known internal fluid-system resistances and the propellant density. The SSME nominally requires a delta pressure of 27 psid for the oxidizer (liquid oxygen) circuit and 4 psid for the fuel (liquid hydrogen) circuit to properly condition the engine prior to start. The Ares configuration would require the SSME to operate at lower flowrate (a delta pressure between 2 and 10 psid for the LOX side and between 0.5 and 10 for the fuel side). Since the engine already met the Ares I ICD requirements for fuel, the off-nominal testing mainly concentrated on targeting lower flow conditions for the oxidizer system.

Due to the lower mass flowrate and correspondingly higher temperatures in the system - below the chill limit but above nominal temperatures - care was taken to avoid reaching the saturation temperature of the fluid. This precaution avoided the creation of additional gas pockets within the SSME that could affect proper thermal conditioning of the engine hardware (e.g. pump bearings). 
Early off-nominal tests successfully chilled at LOX system delta pressures between 10 and 12 psid (tests 902-898 and 902-905). 902-906 was the first test to chill with 6 psid reduced flowrate and was followed by supplemental testing on 902-908. Development engine 0525, used on all of the low propellant bleed testing, was able to be properly thermally conditioned with a delta pressure as low as 6 psid. Test 902-916 demonstrated a low flowrate chill of 2 psid at the lower band of the Ares I ICD requirement. Overall, testing confirmed that the engine could be properly conditioned at low flowrates while maintaining margin to saturation temperatures (see: Figure 3). Furthermore, tests 902-905 and 902-908 demonstrated the ability to start the engine after a low flowrate chilldown (without reverting back to nominal chill conditions prior to engine start).

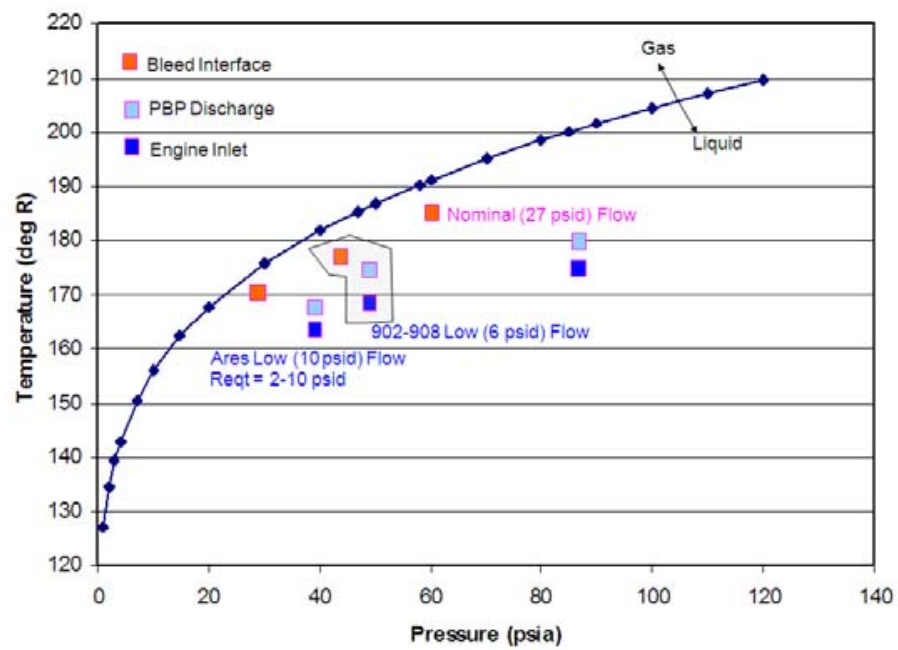

Figure 3. Test 902-908 Margin to the Saturation Temperature at a Variety of Instrumentation Locations during Thermal Conditioning

\section{Low Inlet Condition Start Sequence}

During off-nominal test planning, synergy with the Constellation Program - Ares I launch vehicle development - was considered and focused SSME testing to a variety of low inlet condition starts for upper-stage emulation. Since the SSME utilizes a tank head start (versus that of helium spin start common to other rocket engines), low inlet pressure and temperature testing was needed to determine the possibility of starting within the Ares I ICD requirements.

Prior to the 2008/2009 off-nominal test series, the SSME had undergone low inlet condition testing during the 1996 Reusable Launch Vehicle (RLV) test series with Engine 3001 (a Phase II Technology Test Bed engine) [3]. The benefits of earlier testing were applied to the modeling of start sequence changes, however, the later series of testing directly targeted the lower start inlet conditions associated with the J-2X Upper Stage Engine - specifically lower fuel pressures, oxidizer pressures, and oxidizer temperatures. Using the J-2X ICD as a guide for test planning, the SSME incrementally stepped down to the J-2X operating regime with each successive test by modifying the start sequence commands within the engine control computer (controller) software (see: Figures 4 and 5). Incremental steps were needed as small changes in the valve timing and slew rates can cause priming order differences between the combustion chambers and large temperature spikes. Large temperature spikes in the past have been associated with hardware damage (e.g. turbine erosion) and, thus, avoided. Testing achieved successful starts with LOX conditions up to $5^{\circ} \mathrm{R}$ and 53 psi lower than the Block II SSME ICD. Correspondingly, the starts were also achieved simultaneously with fuel pressures up to 5.75 psi lower than the Block II SSME ICD. Moreover, testing achieved successful engine start within the sea-level equivalent conditions of the J2X ICD bands.

To build upon previous testing, the configuration differences between the Phase II and the Block II engines were assessed. One major concern was the slower fuel pump start associated with the Block II engine, specifically the slower turbopump speed buildup at lower $\mathrm{LH}_{2}$ inlet pressures [3]. These pump characteristics and associated valve schedule software constraints led to the necessity of the aforementioned iterations in inlet conditions. Furthermore, because of the slower start characteristics, ignition confirm Pad 
Abort Limit (PAL) start logic used for space shuttle flight operations was altered slightly - delaying the confirm times properly addressed the slower start.

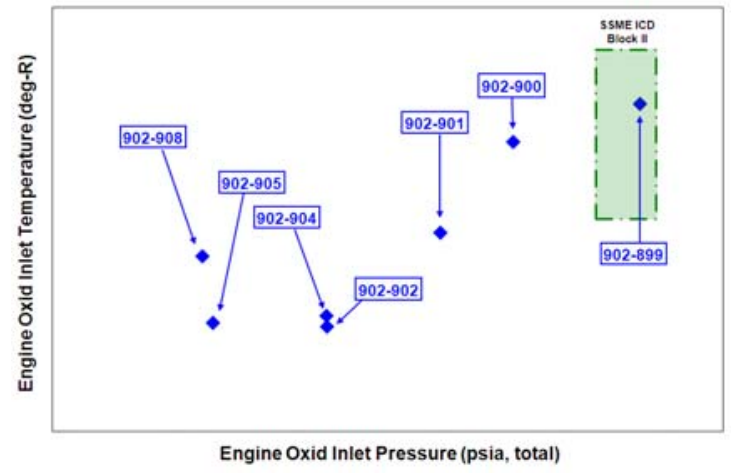

Figure 4. SSME Expanded LOX Inlet Conditions [2]

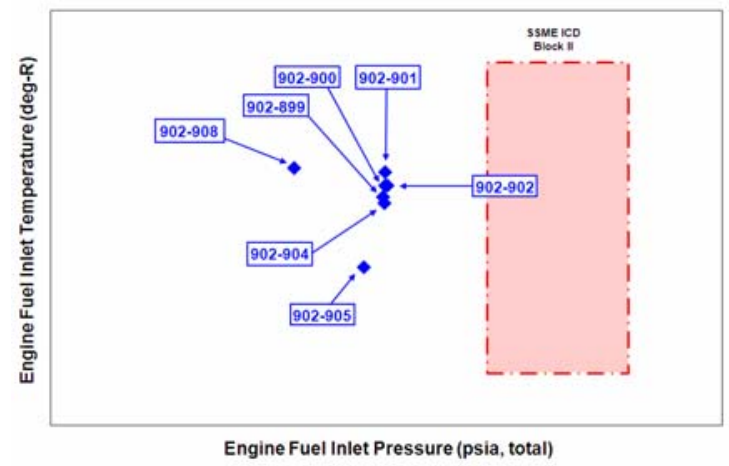

Figure 5. SSME Expanded Fuel Inlet Conditions [2]

Additionally, testing of the objective required a small hardware modification; the engine fuel preburner augmented spark igniter (ASI) oxygen orifice size was increased for 902-902 as there was a risk that the reduced oxidizer flow to the igniters would not have enough energy to ignite the fuel preburner.

Each incremental test utilized the mature SSME transient model to minimize temperature spikes in the turbines during startup. Significant modeling efforts allowed the team to properly address any risk prior to every test. In part due to those efforts, no significant damage was observed during disassembly inspections of the pump turbines throughout the test series. After successfully testing across a wide range of inlet pressures and temperatures, the SSME demonstrated its flexibility to changing inlet conditions and its ability to operate within the operational regime of an upper stage engine.

\section{High LOX Inlet Temperature Start}

For the Space Shuttle Program, Launch Commit Criteria (LCC) MPS-25 protected against violating Orbiter ICD LOX propellant inlet condition requirements on launch day. The LCC limits the LOX temperature at the engine interface to a maximum value of $178.0^{\circ} \mathrm{R}$ as warm LOX entering preburners could potentially cause a cold start and a pad abort due to poor OPB combustion. To assist in maintaining this limit, the controller-monitored LCC SSME-20 was established to protect the engine's internal fluid quality by monitoring the Pre-Burner Pump (PBP) discharge temperature measurement as well. Based on the change in temperature between the inlet and preburner, SSME-20's limit of $186.5^{\circ} \mathrm{R}$ is indicative of sufficient margin from the maximum inlet temperature limit.

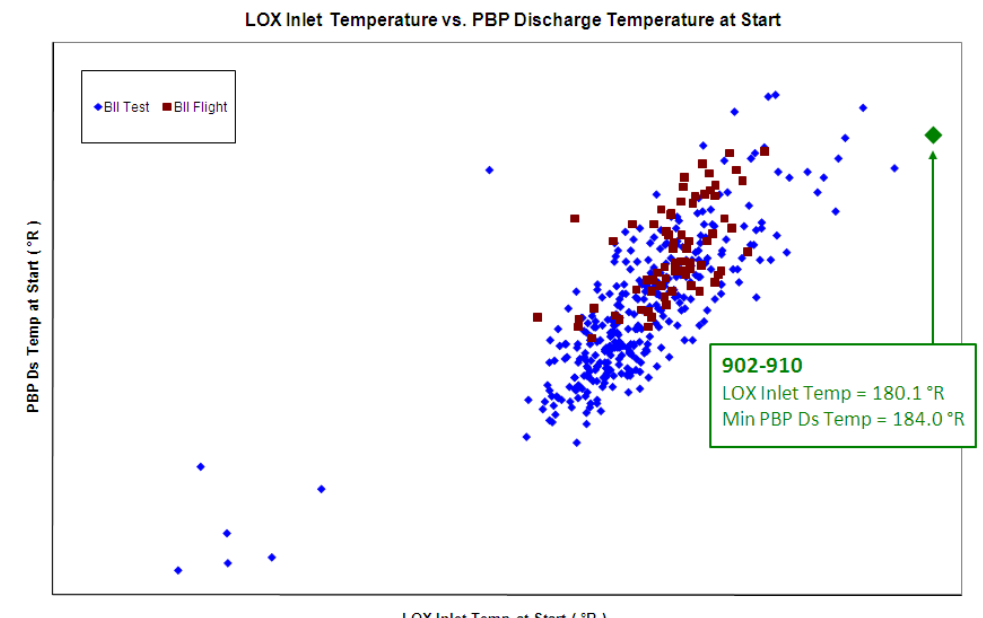

Figure 6. PBP Discharge and LOX Inlet Block II History 
For the off-nominal test series, test 902-910 evaluated the effect of higher LOX inlet temperatures on the engine start transients. The objective of the test was to investigate the correlation between the inlet temperature and the PBP discharge temperature (at $186.5^{\circ} \mathrm{R}$ ). Based on prior ground-test experience with the Block II SSME, an engine test at the PBP discharge temperature limit would require the LOX inlet temperature to be approximately $181.7^{\circ} \mathrm{R}$. Therefore, the target LOX inlet temperature for test $902-910$ was $181.5^{\circ} \mathrm{R}$. Correspondingly, to test around the SSME-20 limit, the PBP discharge temperature engine ready limit was raised to $188^{\circ} \mathrm{R}$ within the software (based off the maximum Phase II ground test experience at $\left.188.3^{\circ} \mathrm{R}\right)$.

Test 902-910 achieved LOX inlet start temperatures of $180.1^{\circ} \mathrm{R}$ and a PBP discharge temperature of $184.0^{\circ} \mathrm{R}$ (See: Figure 6). Post-test analysis of the start data suggests that the engine can operate within a wider start box as the test had good OPB combustion and an acceptable start. However, the team did note that engine 0525 (used for test 902-910) had historically good combustion and may mask the effects of higher LOX inlet temperatures on an engine with poor OPB combustion.

\section{Power Level \& Mixture Ratio Excursions}

Power level and mixture ratio excursions have been of particular interest throughout the lifespan of the SSME. These tests reveal the true capabilities of the engine by expanding its potential operating points. This type of testing began as early as 1977 on test 902-065 (15 seconds at 50\% RPL) and 1978 on test 901-079 (650 seconds at 50\% RPL). Other modern era, 1996, power level excursion testing was completed on tests 902-638 and 902-641 in support of the aforementioned Reusable Launch Vehicle (RLV) study. Similarly, Engine 3001, used during Technology Test Bed (TTB) testing, reached power levels as low as $17 \%, 22 \%$, and $25 \%$ RPL for 4.5 second durations. The lowest power level achieved with the current Block II version of the engine has been 63\% RPL. That particular power level provided synergy with the Constellation Program to emulate an Ares I Upper Stage engine. The SSME would be required to run at $63 \%$ RPL at a mixture ratio of 5.50. If it was needed as a temporary "gap filler" for early Ares flights, the team decided to emulate those power level and mixture ratio requirements during the test series.

Power level and mixture ratio excursion tests were run on three tests in 2008 (902-905, -908, and 910). Test 902-908 operated at the Ares I start conditions and power level and successfully emulated vehicle requirements. The mixture ratio on 902-908 ran outside the Ares I ICD band, at 5.720, due to a $2.8 \%$ fuel flowmeter shift during start. The start shift was attributed to the rotor's response to the power level specific flow vortices within the compact design of the Low Pressure Fuel Duct (LFPD) and was mitigated on test 902-910 by adjusting controller software constants to account for the shift. Test 902-910 successfully started to the Ares I mixture ratio and power level requirements (and repeated the $2.8 \%$ fuel flowmeter shift as predicted). Furthermore, data collected on 902-910 characterized the engine's mainstage performance at varying mixture ratio and power level conditions.
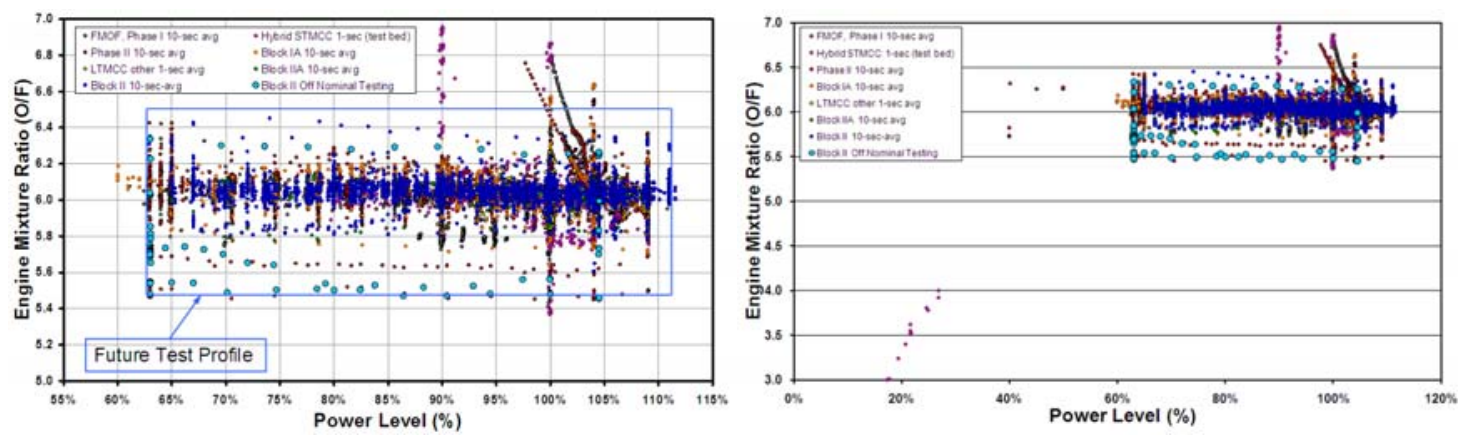

Figure 7. Summary of SSME Tested Power Levels and Mixture Ratios

Through the incorporation of this off-nominal testing, the SSME has successfully demonstrated operation beyond its requirements for the Space Shuttle Program, see Figure 7. Data from test 902-910 illustrated that system effects of mixture ratio changes with power level are more pronounced than was previously documented and allowed the PWR steady-state modeling team to update performance maps within the engine Power Balance Model (PBM). As a result of the PBM updates and a reassessment of prior flight performance, NASA Level II generated an MPS inventory update and gained $200 \mathrm{lbm}$ of Ascent Performance Margin (APM) for the Space Transportation System (STS). For that reason, the test series not 
only demonstrated the flexibility of the engine design to meet future vehicle requirements, but it also resulted in a direct benefit for space shuttle launch operations.

\section{Low Helium Pressure Pneumatic Shutdown}

Margin for flight rules on launch day increase the probability of mission success. Specifically, in the event of a helium leak during ascent, the vehicle would contain a lower than nominal helium supply pressure for the SSME's pneumatic systems during shutdown. As a result, there is uncertainty in the ability of the SSME to perform an emergency pneumatic shutdown during that scenario (as a nominal shutdown is by hydraulics). By testing the engine's pneumatic shutdown under low helium pressure, the team evaluated the possibility to increase engine operation time by assessing margin to flight rules. For the Space Shuttle Program, longer engine operation would have increased the orbiter's chances of reaching a Transatlantic Abort Landing (TAL) site if required.

Valve responses were first tested separate from the engine at the Hardware Simulation Lab (HSL) at MSFC. This testing allowed for the determination of the effects of low helium pressures on the individual valves. With this data, the team could properly justify moving on to system level testing. However, because of the possible hardware damage induced by an errant pneumatic shutdown, given the lower helium pressures, further assessment was needed prior to a full-scale hot fire test. Flight Readiness Tests (FRTs), where the valve and command sequence checks occur prior to every test and flight, allowed for testing valve responses on the engine without loading propellants. Therefore, prior to test 902-916, the FRTs provided the first step in evaluating a low helium pneumatic shutdown. During these functional tests, a low helium shutdown sequence was added to the nominal set of functional checks and allowed for a direct comparison between nominal and low helium pressure conditions. The SSC demonstration of the low helium pneumatic shutdown came in 2 phases: one FRT at nominal helium pressure, 770 psia, and one at the lower helium pressure, 520 psia, as seen in Figure 8.
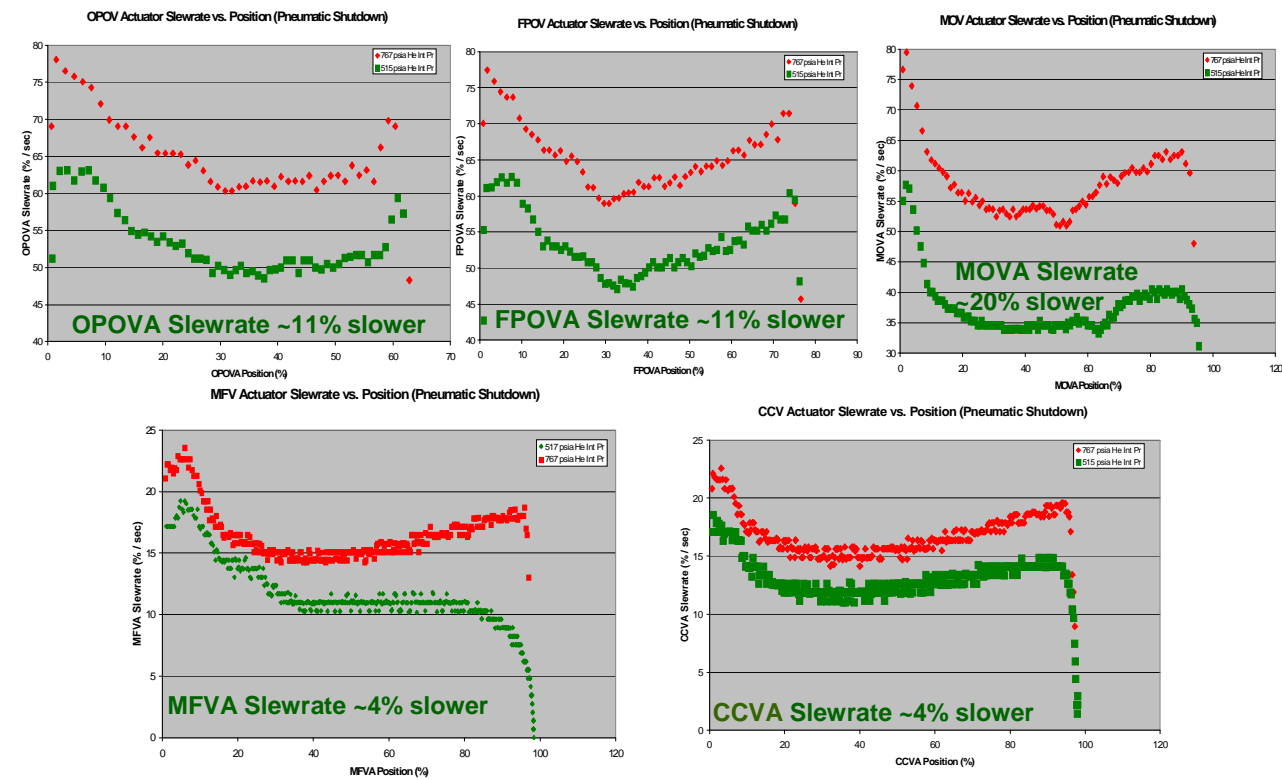

\section{Figure 8. Low Helium Pressure Pneumatic Shutdown Valve Actuator Rate Comparison (Nominal Shutdown, Red vs. Low Helium Shutdown, Green)}

The FRTs utilized the same valve profiling as planned for test 902-916. The hydraulics were shut off halfway through the FRT to initiate a hydraulic lockup and a pneumatic shutdown. Upon shutdown initiation, the pneumatic system successfully took control for both the nominal and low helium pressure conditions. With a pneumatic shutdown, the engine purges turn on and the engine helium interface pressures drop to 700 psia and 470 psia for the nominal and low helium pressure conditions respectively. Because of the lower helium pressures, the valve responses and actuator closure rates are lower. This is a result of the engine's pneumatic control assembly (PCA) requiring a longer duration to fill with helium and 
delaying valve actuation. As a result, the engine purges using the same helium supply take longer to shut off.

While this testing successfully demonstrated the capability of the SSME to shutdown pneumatically with off-nominally low helium pressures, the FRT is only a partial simulation. Without the system pressures generated by a hotfire condition, the preburner purge check valves would open later and the POGO GOX Control Valve (GCV) would be delayed because of the lower helium pressure conditions. Also, propellant loading on the valves from flow during hotfire is not captured with an FRT. Therefore, a full-scale hotfire test would be needed to further evaluate this objective; however, the low helium pressure pneumatic shutdown testing performed indicated no potential roadblocks.

\section{Post-Hotfire Drying Modifications}

Through the off-nominal test series, a major process supplementary to hot firing the engine was also explored - engine drying. Following each test, the engine requires extensive drying to reach the required dewpoint check limit of $27 \mathrm{ppm}$. The main intent of the off-nominal drying experimentation was to demonstrate the capability to reduce engine drying time. Shorter drying times can lead to faster engine turnaround times and lower the cost of testing. Additionally, for the Space Shuttle Program, shortened drying time would have also assisted in a quicker turnaround after on-pad launch abort for launches with small launch windows (e.g. STS-400, see Figure 9). In order to improve the engine drying time, a firm understanding of the current drying process within the engine's complex flow paths was needed by the team.

Drying the engine after every hot fire is to purge the systems of water that is formed during engine hotfire. These purges are mainly in the hot gas system and minimize the potential for pump bearing corrosion and prevent water from being trapped in the lines and auxiliary components. Ice formed during the cryogenic chill could lead to catastrophic engine damage upon ignition; for example, valves freezing closed or blockage of engine coolant paths.

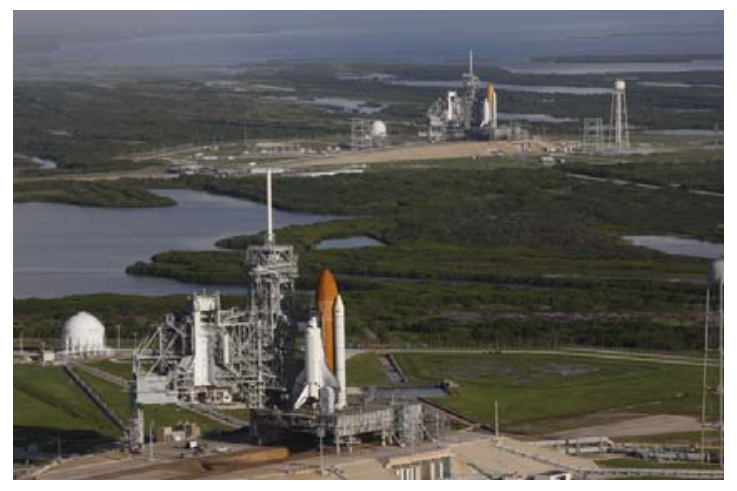

Figure 9. Atlantis STS-125 Hubble Space Telescope Servicing Mission and Endeavour STS-400 for a Possible Launch on Need Mission [5]

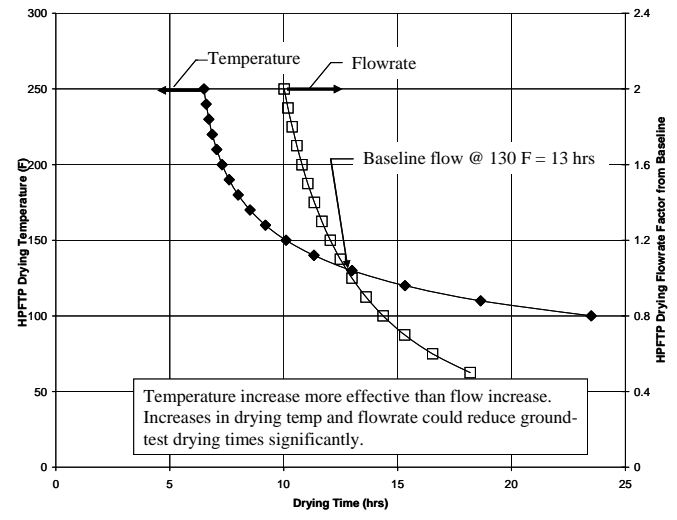

Figure 10. HPFTP Drying Temperature and Flowrate Factor from Baseline vs. Drying Time

The drying experiments were implemented on tests 902-899 through 902-912 by elevating the purge temperature, changing the vent path through the HPFTP, or increasing the purge flow rate. For the elevated purge temperature tests the facility heater setting was adjusted from 165 degrees Fahrenheit to 180 degrees Fahrenheit. Figure 10 illustrates that drying time decreases with moderate increases in drying temperature. For other tests, the HFPTP flow circuit was changed such that some areas were vented instead of pressurized. That change in procedure did not hinder the drying process; however, it did not sufficiently nor consistently decrease the drying time.

Ultimately, the drying experimentation performed on tests 902-899 thru 902-912 proved inconclusive as the sample size of testing was limited. The one common thread, however, was that of the off-nominal tests in which the drying time was monitored, only three tests were above $100 \mathrm{ppm}$ at 8 hours of drying. These three tests also had anomalous conditions associated with the drying procedures. On 902904, venting at N11.4 on the HPFTP introduced an increased amount of moisture in the area, a condition 
easily incorporated into drying logic. On 902-905, poor weather conditions interfered with engine conditions and, conceivably, the overall moisture of the engine. Lastly, on test 902-912, the addition of an earlier dewpoint sample may have introduced more moisture into the system.

The off-nominal test series ended too quickly to properly allow for full characterization of the system. The data collected during the drying experiment test series, however, did provide the team insight for future experimentation as the HPFTP dry requirements (27 ppm) maybe too restrictive based on the available data.

\section{OPERATIONAL DEMONSTRATIONS}

\section{Low HPOTP IMSL Flight Rule Demonstration}

Gaseous helium, supplied by the shuttle orbiter, is used as a barrier within the Block II High Pressure Oxidizer Turbopump (HPOTP) to separate the turbine-end hot gas from the pump-end liquid oxygen. This design of the HPOTP is called the Intermediate Seal (IMSL) and crossover between the two substances has been identified as a critical failure mode of the pump/engine. Space shuttle flight rule A5153, which allowed the engine to operate and then shutdown at a HPOTP IMSL pressure of 60 psia in the event of an abort scenario [6], had never been tested. To prevent low helium pressures within the IMSL, the engine operates with a minimum redline of 159 psia; however, this redline can be inhibited in the case of an abort scenario to keep the engine running longer. The flight rule would be invoked when one engine has already been shut down and two engines were still running at 109\% RPL with a helium leak (on either engine). Therefore, the ultimate goal of the flight rule was to keep two engines running (including the one with the helium leak) up to the point where the orbiter could have reach a TAL site or perform an RTLS on a single engine. Demonstration of the flight rule was recommended by the Astronaut Office and the MOD console operators at Johnston Space Center (JSC) after consultation with the engineering team.

The test plan utilized a two step approach to demonstrate the flight rule by first modifying the engine controller's IMSL redline software value and then lowering the facility supplied helium pressure. The first test, 902-899 went down to an IMSL pressure of 85 psia (under nominal facility helium supply pressure of $750 \mathrm{psi}$ ) to verify the analytical model and increase confidence in the proper helium supply regulator setting for a 60 psia test. The second test, 902-900, stepped down to an IMSL pressure of 60 psia at $109 \%$ RPL and successfully demonstrated engine operation at flight rule conditions. It should be noted that the shutdown was from a nominal IMSL pressure and 67\% RPL.

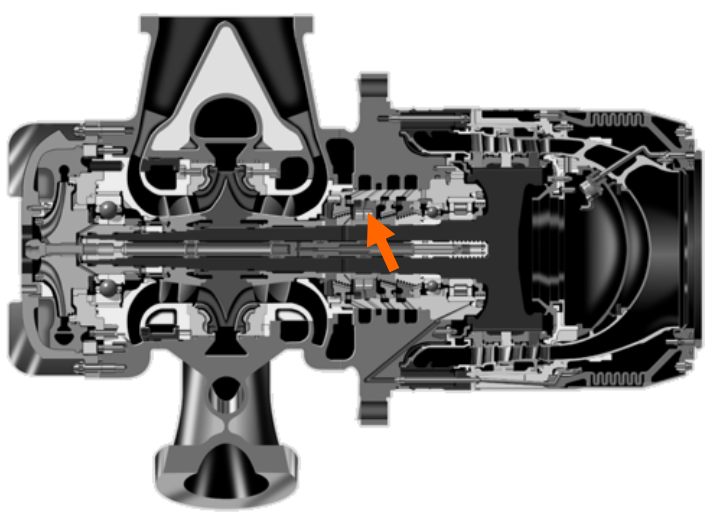

Figure 11. Block II HPOTP \& IMSL Location

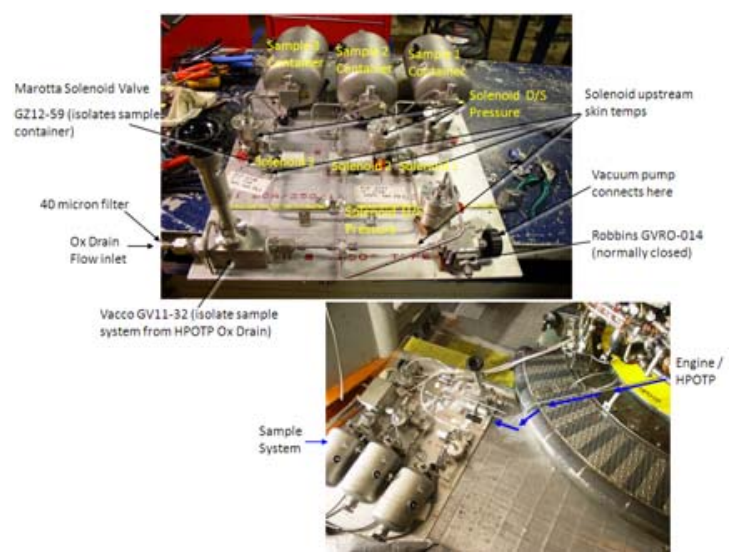

Figure 12. ISML Crossover Detection System \& Test Stand Set-up

Additionally, to confirm successful operation, a special gas sampling system was constructed by SSC Test personnel using three Cosmodyne Type TTU-131/E sample bottles attached to the HPOTP oxidizer drain. The system determined, post-hotfire, if crossover occurred during the demonstration by gas chromatograph analysis. The samples collected on tests 902-899 and 902-900 indicated no hydrogen crossover when compared to control samples taken during pre-test FRTs. 


\section{Low Fuel NPSP Flight Rule Demonstration}

Net Positive Suction Pressure (NPSP) is, simply, the margin between the total pressure of a fluid and its vapor pressure. The parameter is used in turbomachinery to identify how close a pump is to cavitation (the point when the local fluid pressure approaches the vapor pressure of the fluid). Cavitation at a pump inducer will cause the shaft speed to increase and may cause performance problems and structural damage - including pitting on metal surfaces due to gas bubble collapse. As a result, low propellant NPSP at the engine interface is a concern for flight operation and the Space Shuttle Program protected for low fuel (hydrogen) NPSP per flight rule A5-155: "Main engines shall not be allowed to run below a minimum NPSP of 3.0" [6].

Previous low fuel NPSP hot-fire testing was conducted in 2006, with LPFTP 82407 on test 902871, to allow a flight change down to 3.5/3.0 psi as the prior flight rule did not adequately protect the Block II SSME from low fuel NPSP during vehicle ascent (e.g. during ET ullage leaks and GH2 repressurization failures). The aforementioned testing achieved current flight rule conditions at $67 \%, 80 \%, 95 \%$ and $104.5 \%$ RPL with no significant LPFP/HPFP head or efficiency fall off at or below 3.0 psi. The flight rule was changed in February of 2007; however, to verify the limited experience and analysis used in the flight rule change, it was decided to demonstrate operation below the low fuel NPSP flight rule with an additional unit to assess repeatability of LPFTP suction performance.

The test plan utilized a two step approach to demonstrate the flight rule by establishing a baseline comparison on the first test and then to systematically step down at multiple power levels on the second test. The first test, 902-899, characterized LPFTP 2234's performance under nominal facility fuel vent conditions. The second test, 902-901, stepped down from 104.5\% RPL to 67\% RPL and successfully demonstrated engine operation at or below flight rule conditions with no significant speed increase or head fall off. Testing demonstrated a more than 0.5 psi improvement upon the flight rule. Moreover, it should be noted that the engine was successfully shutdown at an NPSP value below flight rule conditions.

As a precaution for testing, LPFTP speed redlines were established for each power level based on speed predictions. The individual redlines were set approximately 1,000 RPM above the predicted. Furthermore, during hotfire, the different NPSP values were obtained by monitoring the calculated engine NPSP and adjusting the facility fuel tank vent accordingly.

Overall, the testing assessed the repeatability of LPFTP performance, demonstrated the robustness of the design, and provided additional confidence for flight rule operation.

\section{Software Failure Insertion Demonstration}

In 2008, the SSME Software group developed a special version of ground-test-only software, identified as AD05 and based on STS-125 mission software, in which simulated failures and commanded mixture ratio changes can be induced during hotfire. Version AD05 is the only Advanced Health Management (AHM) software version capable of failure insertion as previous failure insertion testing had been conducted using non-AHM software. Possible failures include halting processing on different Digital Computer Unit (DCU) channels, disqualifying controller input and output electronic channels, inducing engine failure modes (electrical and hydraulic lockup), failing different valve actuator channels, and initiating a Major Cycle Restart (MCR). After discussion between PWR and NASA MSFC, the team agreed to induce an MCR on test 902-909 during the Engine Start phase.

In one major cycle, at 20 millisecond intervals within the DCU, all engine controller processing takes place. A MCR allows the controller to reinitialize after an anomalous event occurs in data processing or health evaluation. For test 902-909 a direct call to the MCR routine was inserted into the software for 3.62 seconds after engine start and no issues were noted during the actual hotfire. A standard post-test controller memory dump verified that the MCR occurred as there was the expected 20 millisecond delay in updating the controller time reference known as TREF.

\section{LOX Bleed Interruption Testing}

To prepare an SSME for launch, both the cryogenic oxidizer (liquid oxygen) and the cryogenic fuel (liquid hydrogen) are "bled" through the engine hardware to allow the engine to properly "chilldown", see Figure 13. Improper thermal conditioning of the engine could affect engine start-up (potential pad abort scenario) as the cryogenic fluid would flash to its vapor state as it impinged upon a warmer surface prior to entering the preburners (which is mainly a concern for LOX). Therefore, fuel and oxidizer thermal conditioning of the engine was protected on launch day by space shuttle Launch Commit Criteria (LCC) MPS-33 and MPS-24 respectively. 


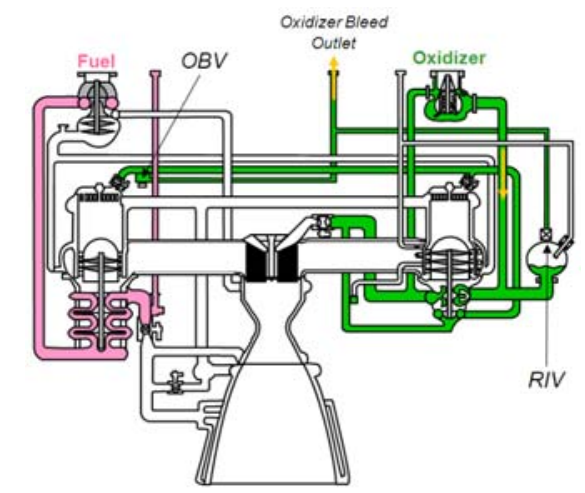

Figure 13. SSME Chilldown / Thermal Conditioning Flow Diagram

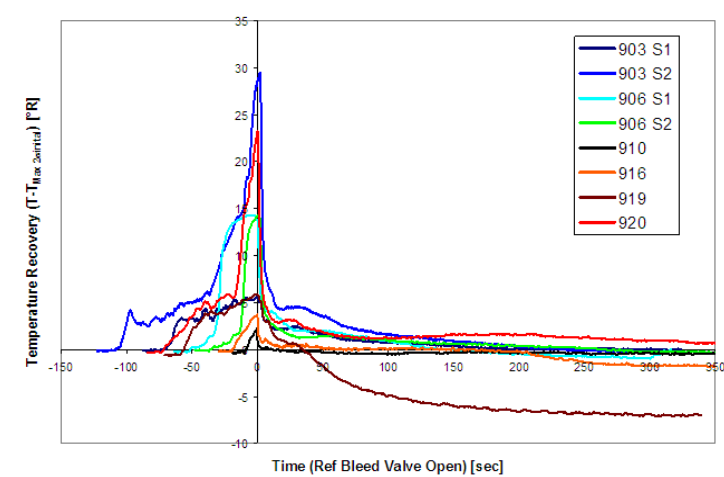

Figure 14. Temperature Recovery vs. Time from Bleed Flow Reinitiated

Up until March $24^{\text {th }} 2010$, only bleed interruptions of 1 minute total duration were allowed on the fuel side per MPS-33 (up until five minutes prior to engine start). MPS-24, which protected for LOX thermal conditioning, did not allow for any interruptions within 60 minutes of engine start and required continuous bleed flow. The LCC cited that historical "SSME test stand experience" as the basis for the requirement. However, when the test history of bleed interruptions was researched and compiled in 2008, analysis indicated that the LCC MPS-24 LOX bleed flow requirement was overly conservative and could be relaxed. Additionally, flight experience from STS-44 supported this claim when a LOX Revert Recovery due to a late replenish (at E/S-39 minutes) caused an 80\% reduction in engine LOX bleed flow during two 8-second interruptions. For that flight, the internal LOX temperature on all three main engines fully recovered within 2 minutes. Therefore it was decided by the PWR and MSFC teams to validate the SSME's ability to recover from LOX bleed interruptions within 60 minutes of engine start.

There are two types of LOX bleed flow interruptions on launch day: full and partial interruptions. A full LOX bleed flow interruption stops all flow through the engine due to MPS troubleshooting (e.g. STS-44). This was simulated on tests 902-903, 902-906, 902-919, and 902-920 by closing the facility downstream bleed valve below the engine bleed interface. A partial LOX bleed interruption occurs with a Controller Reset (CR) and is the most likely scenario for a short LOX bleed interruption on launch day as a CR is used to re-qualify engine instrumentation after inadvertent disqualification due to MPS tanking procedures. During a CR, the engine bleed valves are closed and the Recirculation Isolation Valve (RIV) opens. LOX bleed flow short-circuits the Oxidizer Bleed Valve (OBV) and continues to flow through the RIV. This form of interruption was tested on 902-910 and 902-916 by issuing a CR command to the controller.

Figure 14 summarizes the results from the six tests (8 samples) of LOX bleed interruptions during the off-nominal test series and illustrates the engine's ability to recover from interruption of various durations prior to 5 minutes before engine start. Each test varied by the amount of time the engine or facility valve was closed and at what thermal conditions the LOX was at prior to the interruption. Overall, by evaluating the rise and recovery of the fluids' temperature and margin to saturation, the SSME exhibits rapid recovery when bleed flow is re-established. Testing demonstrated that interruptions of short durations should not have an effect on thermally conditioning the engine and, therefore, the start sequence.

As a final note, due to the results from testing, a change to LCC MPS-24 was pursued in early 2010. LCC change notice (LCN) 01309 was approved on March $24^{\text {th }} 2010$ and altered MPS-24 to allow LOX bleed interruptions up to 30 seconds until nine minutes prior to engine start to improve launch probability. The nine minute duration was chosen to align with the T-9 minute hold within the space shuttle launch countdown.

\section{Fuel System Purge Interruption Testing}

As previously mentioned, during the launch day countdown, the engines are chilled down using liquid oxygen and liquid hydrogen to thermally condition the engine prior to start (see: Figure 13). However, the downstream combustion devices are isolated from the cryogenic bleed flows (e.g. nozzle, main combustion chamber, and pump preburners) are purged with ground supplied gaseous nitrogen $\left(\mathrm{GN}_{2}\right)$ to maintain a dry environment within the engine to prevent intrusion of environmental moisture (which 
would ice during propellant introduction). Also, the purge addressed pre-start flammability issues as it prevents the accumulation of gaseous hydrogen that may leak from seals/joints. However, purging solely with $\mathrm{GN}_{2}$ is inadequate since liquid hydrogen is cold enough to condense and freeze nitrogen. A fuel system purge (FSP) with gaseous helium prevents nitrogen from accumulating in the coldest areas of the engine (near the MFV and in the HPFTP turbine coolant tubes) and ensures that all $\mathrm{GN}_{2}$ is expelled from the fuel system prior to engine start.

The LCC that monitored the proper function of the FSP (SSME-09) came into conflict when using a Controller Reset (CR) during the countdown. Since a CR momentarily interrupts the FSP (due to deenergization of the pneumatic assembly's FSP solenoid during controller standby checkouts) and SSME-09 did not allow for any interruptions of the FSP, there was a desire from the PWR and MSFC teams to reconcile the discrepancy and prevent an unnecessary scrub on launch day.

A controller reset was performed on test 902-910 to validate previous modeling and previous test experience that illustrated a short purge interruption of 30 seconds would not allow internal gas temperatures to drop below the threshold for solid nitrogen formation (as the ground supplied $\mathrm{GN}_{2}$ purge would not be interrupted by a CR). PWR thermal analysis, seen in Figure 15, indicated that it would take sixty seconds before temperatures drop below the nitrogen ice boundary. In addition, the engineering staff wanted to verify the ability of the system to perform Controller Reset and recycle into Purge Sequence Number 3 (PSN3) within 30 seconds.

On test 902-910, the controller reset and recycle to PSN3 was completed in just nine seconds. The drop in FSP pressure measurements verified that the FSP had been terminated during the CR. Post-test analysis did not reveal any indications of ice formation and, therefore, the SSME Flight Operations team pursed an LCC change to SSME-09 to allow interruptions up to 30 seconds in duration followed by a 5 minute reinstatement period (aligned to match the LCC MPS-33 fuel bleed requirements). The changes to the LCC, per LCN 1288R1, were approved on July $29^{\text {th }}$, 2009, again improving launch probability.

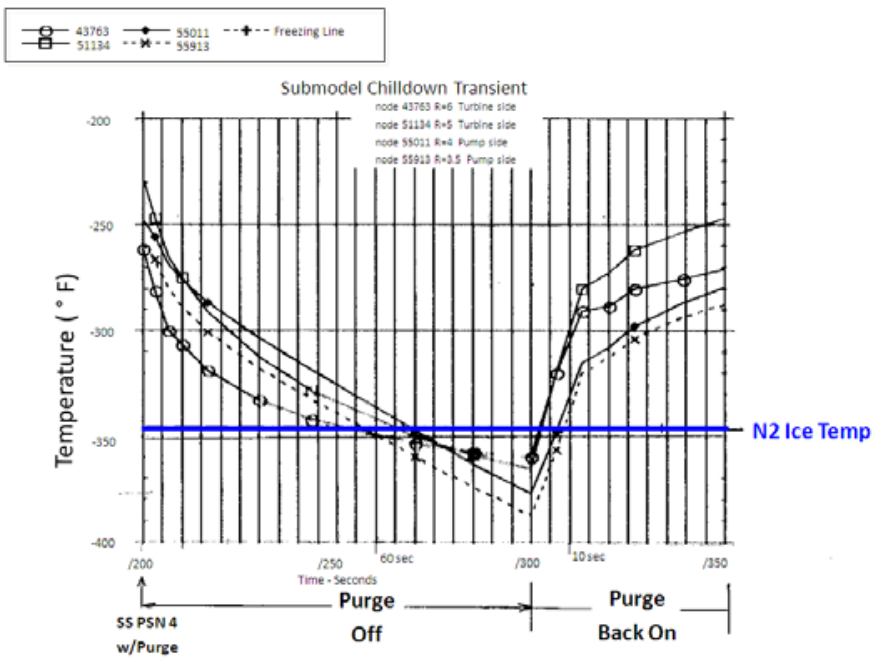

Figure 15. Model of Purge Interruption affect on $\mathrm{GN}_{2}$ Temperatures during PSN4

\section{LOX Purity Sampling}

A liquid oxygen (LOX) sampling system was used on tests 902-919 and 902-920 to investigate the effects of LOX purity on SSME performance and to verify the current theoretical gains. Improved gains could be used by NASA Level II to help assess ascent performance and make better determinations of ascent margins as low purity during ground testing can affect flow calibration used for flight software inputs. A test with low LOX purity can result in flying an engine with a lower oxidizer-to-fuel mixture ratio as the engine will not require as much oxidizer to maintain chamber pressure (due to higher LOX purity seen on launch day). That condition results in flying with more LOX than is needed for a given mission and that difference in margin could be the difference between achieving the planned orbit or having to abort (e.g. low fuel level cutoff) due to unplanned ascent performance dispersions. 

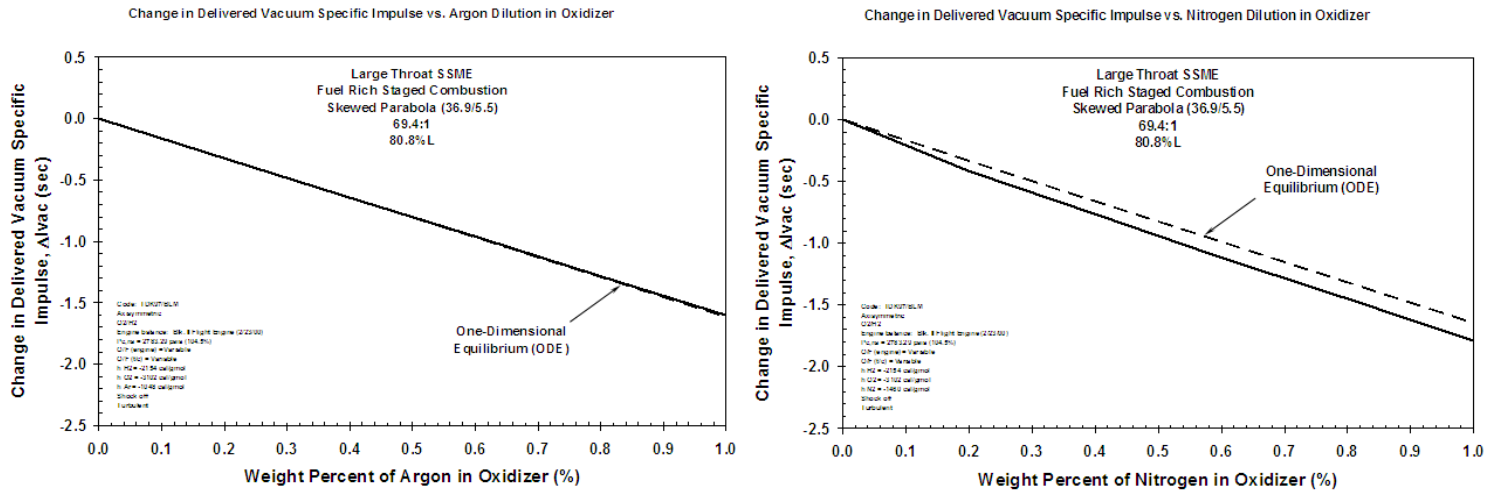

Figure 16. Theoretical TDK/ODE effects of LOX impurities on SSME performance

Two Dimensional Kinetic (TDK) and One-Dimensional Equilibrium (ODE) modeling illustrated that an impurity in LOX results in lower engine specific impulse (Isp). Argon is the main impurity for delivered LOX while a nitrogen impurity may be introduced, during hotfire, as gaseous nitrogen is used to pressurize the facility LOX tank. SSC specifications allows for $99.2 \%$ LOX purity by volume before hotfire and, according to modeling, would allow for a 1.6 and/or 1.2 second loss in Isp respectively per impurity. Furthermore, within the SSC A-2 test stand LOX tank, nitrogen dilution at the gas/liquid interface can reach $100 \%$ pure liquid nitrogen and it is estimated that there is between $2 \%$ to $14 \%$ nitrogen in stratified layers atop the liquid LOX column. It is that $\mathrm{LN}_{2}$ which might be ingested at low tank levels during hotfire and decrease engine performance. This theory was supported by historical documentation (e.g. Thor, Atlas, $\mathrm{J}$-2) that stated high levels of gaseous nitrogen dilution can occur under specific pressure and temperature conditions which are well within the SSME operational region. Additionally, a drop-off in Isp toward the end of SSME tests 901-670, 904-170, and 904-279 was speculated to be the result of liquefied gaseous nitrogen ingestion, from the tank ullage during low level operation, and supported this claim. However, further examination of 901-670 has shown that nitrogen and argon dilutions were not contributors to the inrun Isp change; rather it was a result of the thrust profile and flow calibration.

The objective of 902-919 was to obtain two LOX samples for composition and purity analysis. This would be accomplished by taking a sample early in the test and then taking a second sample when the level of LOX in the tank was predicted to be significantly lower. To collect samples, a LOX sampling panel was fabricated and installed on level 7 of the A-2 test stand underneath the LOX run tank. Sample containers were evacuated to a vacuum prior to test collection.
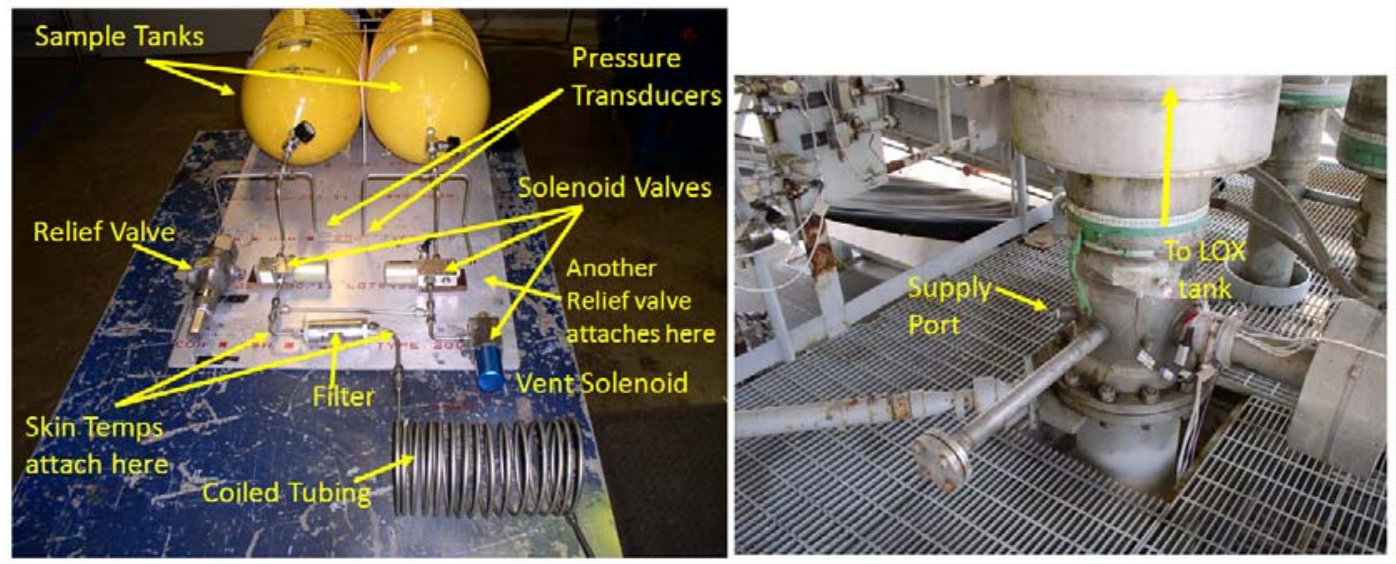

Figure 17. A-2 test stand LOX sampling system \& location

The first tank sample on test 902-919 did not obtain enough LOX for analysis as the set 15 seconds sample duration did not produce the predicted flowrate. The second tank sample was manually held open longer (for 35 seconds) and captured an ample amount for analysis. Post test chemical analysis of the second sample indicated 99.79\% purity based on contaminants (846 ppm Argon / 1205 ppm Nitrogen). 
Ultimately, due to the first sample's inadequate LOX concentration, a performance comparison could not be completed.

Test 902-920's LOX purity objective was the same as 902-919's: obtain two in-run LOX samples to compare its effect on engine performance (i.e. Isp). Prior to hotfire, with the tank at $84 \%$ capacity, two tank bottom samples were harvested and indicated a LOX purity of 99.84\% (889 ppm Argon / $712 \mathrm{ppm}$ Nitrogen) and 99.82\% (935 ppm Argon / $853 \mathrm{ppm}$ Nitrogen) respectively. The two in-run samples indicated a small $0.27 \%$ drop in purity, during hotfire, as the first sample (at $\mathrm{E} / \mathrm{S}+40$ seconds) had $99.82 \%$ purity and the second (at E/S+480 seconds) had 99.55\% purity. Two post-hotfire tank bottom samples, with the tank at $11.6 \%$ capacity, indicated a LOX purity of $99.31 \%$ and $99.53 \%$ respectively.

A performance assessment of 902-920 results was inconclusive as the observed LOX purity change was too small to produce a measurable performance effect as predicted by the SSME Power Balance Model (PBM). The calculated change in Isp was +0.11 seconds which is well within the stand resolution of \pm 0.6 seconds. Moreover, data analysis indicated a minor decrease in LOX flow which challenges the expectation of an increase in LOX flow from a drop in LOX purity. Overall, no LOX purity performance effects could be detected and the team was unable to confirm or contest model gains. However, 902-920 sampling and testing supports the claim that, even under the most favorable dilution conditions, LOX purity is not a meaningful test stand concern.

\section{TECHNOLOGY DEMONSTRATIONS}

\section{Non-Intrusive Passive Magnetic Proximeter}

Over the course of six tests, during the off-nominal series, PWR-designed non-intrusive passive variablereluctance magnetic proximeters were evaluated for their effectiveness and diagnostic potential for rocket engine rotary systems. Magnetic proximeters offer a unique non-intrusive way to measure vibration, displacement, and speed by exploiting Faraday's law of electromagnetic induction. For rocket engines, electrically conductive rotating machinery will generate a passive time-varying flux while moving in the presence of the proximeter's internal magnet; and it is that voltage potential that can be obtained and processed into usable data. Because of the passive and non-intrusive nature of the device, it offers great advantages for monitoring internal structural components that would otherwise be out of reach by traditional instrumentation.
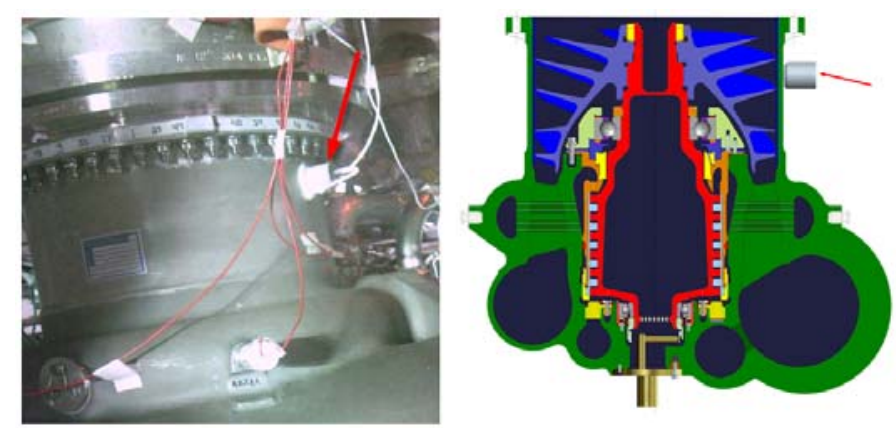

Figure 18. Proximeter Installation on LPOTP

Beginning on test 902-911, additional measurements of the SSME LPOTP, LPFTP, and HPFTP rotor vibrations and speed were passively taken with proximeters. Also, in support of a hardware fatigue investigation, an attempt was made to use proximeters to measure the motion of the Fuel Preburner (FPB) inspection port plug.

Test data indicates that proximeters offer an advantage in signal-to-noise ratio (SNR) when used for detecting pump harmonics (as seen in Figure 19). In addition, testing indicated that the proximeters were able to detect cavitation responses better than standard accelerometer instrumentation, as seen in Figure 20. However it should be noted, due to the limited number of test samples, more testing is needed to properly calibrate the proximeter voltage signals into appropriate acceleration, velocity, and displacement information. 


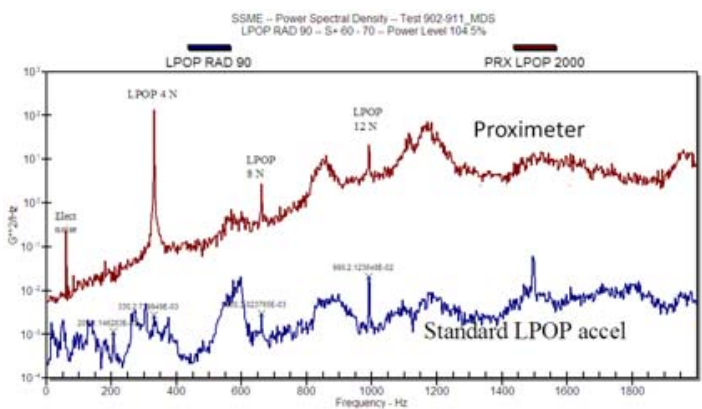

Figure 19. Power Spectral Density Comparison for LPOP Harmonics

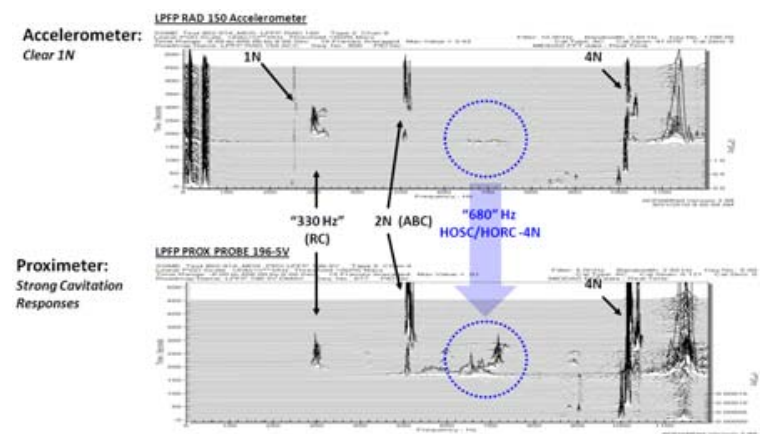

Figure 20. Power Spectral Density Comparison for LPFP Cavitation

Absolute displacement measurements, during the FPB hardware investigation, could not be obtained as further work is needed on deflection histograms. However, the smaller proximeters placed on the FBP plug cap were able to measure relative motion and provided a stronger response to liner resonance than the standard accelerometers used during hotfire.

Blade speed and deflection are useful in determining fatigue life of rotating elements and the proximeters demonstrated the ability to measure the transit time and deflection of each individual blade in the LPFTP inducer. Using a PWR developed tip-time binning algorithm, the team separated the information into a data set for each blade. The individual data sets revealed the characteristics of a single blade; such as deflection and resonance.

\section{Non-Intrusive Ultrasonic Flowmeter}

One of the single most important parameters in evaluating a rocket engine's performance is an accurate profile of the fluid flows within the engine's circuits. Currently, intrusive turbine-style flowmeters are used in measuring cryogenic fluid flow for engines that utilize a feedback control system to monitor and control mixture ratio. However, $\mathrm{LOX} / \mathrm{LH}_{2}$ engines have the disadvantage in which $\mathrm{LOX}$ flowmeters are usually prohibited due to ignition concerns in the oxygen-rich high-velocity high-pressure environment. Early SSME configurations included a turbine style LOX flowmeter until a December 1978 incident in which Main Oxidizer Valve (MOV) fretting caused a LOX fire on engine 2001. A reassessment of the LOX system concluded that the LOX flowmeter was an unnecessary risk to the SSME and was replaced by an equation, within the controller, which back calculates LOX flowrate from fuel flowrate and chamber pressure measurements [1].

The calculated LOX flowrate from controller computation was adequate for flight control, but a measured flow rate was desired for the analysis of abnormal operating conditions and failure scenarios; thus, a non-intrusive ultrasonic flowmeter was desired [1]. A non-intrusive flowmeter has no moving parts and would improve engine / vehicle performance (e.g. measure parasitic pressure drops or obtain tighter mixture ratio control), lower duct weight, and prevent flow distortion due to vortex shedding / cavitation. In addition, ultrasonic flowmeters could be attached and removed as necessary and placed where traditional intrusive flowmeters could not.

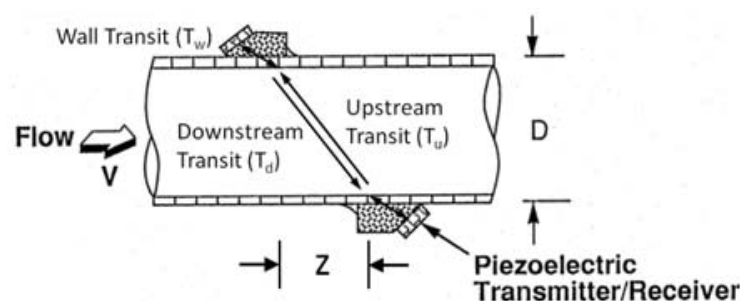

Figure 21. Basic Ultrasonic Flowmeter Diagram

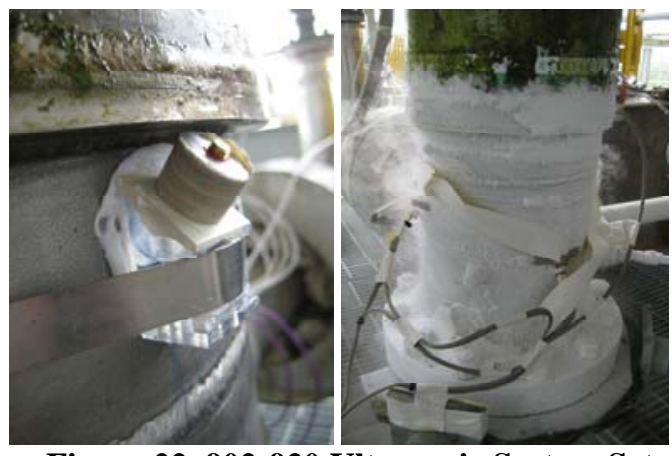

Figure 22. 902-920 Ultrasonic System Setup during SSME Chilldown 
Ultrasonic flowmeters are common within the water, oil, chemical and liquid natural gas industries; however, the cryogenic, acoustic, and vibration environments of rocket engines make it harder to implement the technology for space propulsion applications. An ultrasonic flowmeter uses two piezoelectric transducers to transmit and detect ultrasonic pulses. By measuring the diagonal upstream and downstream transit times, one can measure the flow velocity and temperature using time-domain parameters. Flow velocity is a function of the difference in upstream/downstream transit time and the volumetric flowrate (which can be determined by knowledge of the duct diameter and off-set distance). Other measurements, like fluid temperature, density, and mass flowrate can be determined as well.

The 2009 ultrasonic flowmeter testing on the A-2 test stand facility added to the knowledge gained from previous SSME and RS-27 ultrasonic flowmeter testing which had indicated that:

- Non-hermetic sensors are unreliable due to condensation/frost

- Sensor attachment to duct must not create high localized strain

- Ultrasonic sensors must overcome wall carried noise and improve signal-to-noise ratio

Due to the loss of engine 2208 on test 750-175 in August 1982, in which the piezoelectric transducers brazed to the SSME high-pressure oxidizer duct suffered a HCF crack at the braze/duct interface, all future ultrasonic flowmeters would not be rigidly attached. 2005 testing of ultrasonic flowmeters on the RS-27 test stand LOX feed line allowed the electronics design staff to develop a higher signal-to-noise ratio system and non-straining sensor installation procedures (i.e. hose clamping sensors). The RS-27 facility setup was able to detect and measure the facility LOX flowrate during engine hotfire.

The experimental ultrasonic system was installed on level seven on the SSC A-2 facility for test 902-920. The goal of test 902-920 was to test the practicability of using hose-clamped mounted ultrasonic flowmeters, using COTS devices to measure the transit times, and to demonstrate the ability of one pair of transducers to measure flow via a relay box that switches between upstream and downstream measurements. The ultrasonic flow measurement equipment was enclosed in a nitrogen purged NEMA 4X enclosure while the cable-connected transducers were mounted to the facility LOX run duct with 12 inch stainless steel hose clamps and a cryogenic compatible lubricant.

The benefits of the design changes could not be verified on test 902-920 as no signal was detected during chilldown or hotfire. A post-test investigation indicated that a facility duct weld (along with duct taper and size) had prevented proper signal propagation. Lab testing at the PWR Canoga Park facility confirmed that a significant portion of signal strength comes from multiple wall reflections (versus only having the fluid beam path) and the weld contributed to a 6-fold loss in signal. In total, there was a 54-fold reduction of signal amplitude on test 902-920 when duct taper and size are included as well. More testing is needed to truly evaluate the feasibility of using ultrasonic flowmeters for rocket propulsion applications. However, the engineering team observed no technical roadblocks that would impede the advancement of the technology.

\section{CONCLUSIONS}

Unmistakably, the Block II version of the SSME has proven itself capable of operating beyond the original scope of its design. Performance margin testing coupled with abort scenario and hardware failure demonstrations have provided an enhanced knowledge of the engine's resiliency, and adaptability, to changes in vehicle conditions, mission requirements, or hardware health. Furthermore, advanced measurement technologies which can further enhance the SSME's performance and health monitoring systems were tested and offer promising results for inclusion in future design revisions.

\section{ACKNOWLEDGMENTS}

The highly successful off-nominal test series spanned two years and, thus, required the hard work and dedication of nearly everyone involved in the SSME Program. The authors would like to thank the enthusiastic support provided by the SSC A-2 Test Stand personnel, the NASA MSFC teams, the PWR 
Canoga Park teams, the PWR West Palm Beach turbomachiney team, and the PWR MSFC/Huntsville teams.

Contributing to this paper were Neal Lepsetz, Robert Blomquist, Mike Carlson, Scott Kittinger, Josephine Kao, Lesli Blake, Jerit Wendlandt, Michael Adams, Michelle Tucker, Amira Abdalla, Tao Yu, Christopher Ulrich, Jeffrey Beck, Scott Ward, Kenneth Head, Patrick Arellano, Paul Strauss, Sarkis Barkhoudarian, Matthew Ligon, Steven Comee, Cory Acosta, Jason Hopper, John Ubowski, and Philip Benefield.

\section{REFERENCES}

1. Biggs, Robert E. Space Shuttle Main Engine: The First Twenty Years and Beyond. AAS History Series, Volume 29. American Astronautical Society, San Diego, 2008. Pg 122-125.

2. Bradley, Douglas and Benefield, Philip. "Space Shuttle Main Engine Operational Capability," $57^{\text {th }}$ JANNAF Joint Propulsion Meeting, Colorado Springs, CO, May 3-7, 2010.

3. Bradley, Michael. "Space Shuttle Main Engine Start with Off-Nominal Propellant Inlet Pressures,” $33^{\text {rd }}$ AIAA/ASME/SAE/ASEE Joint Propulsion Conference and Exhibit, AIAA-1997-2687, AIAA, 1997.

4. Hale, Wayne (ed.). Wings In Orbit: Scientific and Engineering Legacies of the Space Shuttle. NASA, Washington, DC, 2011, pg 164.

5. NASA/Troy Cryder. "Space shuttles Atlantis and Endeavour on launch pads”. KSC-08PD-2731. National Aeronautics and Space Administration. [online media database], URL: http://mediaarchive.ksc.nasa.gov/detail.cfm?mediaid=37480 [cited 22 August 2011].

6. “Space Shuttle Operational Flight Rules”, Volume A. NASA NSTS-12820, 2008.

\section{NOMENCLATURE}

\begin{tabular}{|c|c|}
\hline APM & $=$ Ascent Performance Margin \\
\hline ASI & $=$ Augmented Spark Igniter \\
\hline COTS & $=$ Commercial Off the Shelf \\
\hline CR & $=$ Controller Reset \\
\hline DCU & $=$ Digital Computer Unit \\
\hline $\mathrm{E} / \mathrm{S}$ & $=$ Engine Start \\
\hline ET & $=$ External Tank \\
\hline FPB & $=$ Fuel Pre-Burner \\
\hline FRT & = Firing / Flight Readiness Test \\
\hline FSP & $=$ Fuel System Purge \\
\hline GCV & $=$ GOX Control Valve \\
\hline $\mathrm{GH}_{2}$ & = Gaseous Hydrogen \\
\hline $\mathrm{GN}_{2}$ & $=$ Gaseous Nitrogen \\
\hline GOX & $=$ Gaseous Oxygen \\
\hline $\mathrm{HCF}$ & $=$ High Cycle Fatigue \\
\hline HPFTP & $=$ High Pressure Fuel Turbopump \\
\hline HPOTP & $=$ High Pressure Oxidizer Turbopump \\
\hline HSL & = Hardware Simulation Lab \\
\hline ICD & $=$ Interface Control Document \\
\hline IMSL & $=$ Intermediate Seal \\
\hline Isp & $=$ Specific Impulse \\
\hline JSC & $\begin{array}{l}\text { = NASA Lyndon B. Johnson Space Center } \\
\text { (Houston, Texas, USA) }\end{array}$ \\
\hline LCC & $=$ Launch Commit Criteria \\
\hline LCN & $=$ LCC Change Notice \\
\hline $\mathrm{LH}_{2}$ & = Liquid Hydrogen \\
\hline
\end{tabular}

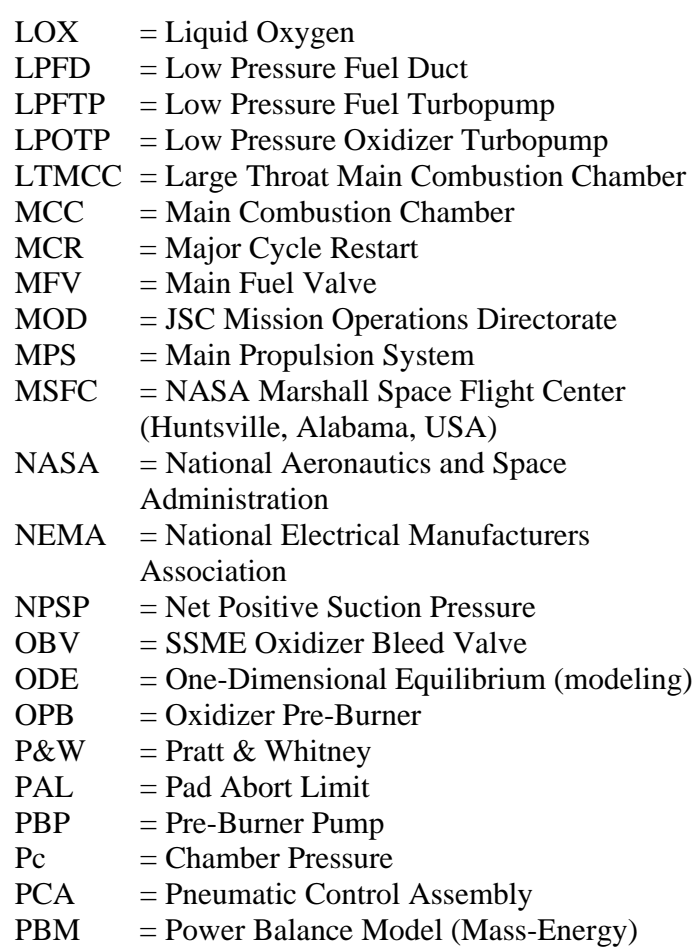




$\begin{array}{ll}\text { ppm } & =\text { parts per million } \\ \text { psia } & =\text { pounds per square inch absolute } \\ \text { psid } & =\text { delta pressure in pounds per square inch } \\ \text { PSN3 } & =\text { Purge Sequence Number } 3 \\ \text { PSN4 } & =\text { Purge Sequence Number } 4 \\ \text { PWR } & =\text { Pratt \& Whitney Rocketdyne } \\ \text { RIV } & =\text { Recirculation Isolation Valve } \\ \text { RLV } & =\text { Reusable Launch Vehicle } \\ \text { RPL } & =\text { Rated Power Level (i.e. \% of design thrust) } \\ \text { RPM } & =\text { Revolutions per Minute }\end{array}$

RTLS = Return to Launch Site; Space shuttle intact abort mode

SSC = NASA John C. Stennis Space Center (Hancock County, Mississippi, USA)

SSME = Space Shuttle Main Engine (RS-25)

STS = Space Transportation System

TAL = Transoceanic Abort Landing; Space shuttle intact abort mode

TDK = Two Dimensional Kinetic (modeling)

TTB $=$ Technology Test Bed 